\title{
Fine Structure of Lymphogranuloma Venereum Agent and the Effects of Penicillin and 5-Fluorouracil
}

\author{
By J. A. ARMSTRONG \\ National Institute for Medical Research, Mill Hill, London, N.W. 7 \\ AND SYLVIA E. REED \\ Department of Bacteriology, The London Hospital Medical College, London, E. 1
}

(Accepted for publication 21 October 1966)

\begin{abstract}
SUMMAR Y
Growth of lymphogranuloma venereum (LGV) agent in HeLa cells has been studied by light and electron microscopy. Infective elementary bodies enter the host cell by phagocytosis, transform directly into the larger forms known as initial bodies, and multiply by fission within a vesicular cytoplasmic inclusion. Later in the growth cycle, elementary bodies are produced by a process involving internal condensation and a progressive reduction in size of the dividing initial bodies. An envelope with two layers, ribosome-like granules and filamentous 'nuclear' material are components common to all developmental forms of the LGV agent. Penicillin prevents multiplication of initial bodies, but not their growth; the very large and vacuolated penicillin forms are similar to bacterial spheroplasts. 5-Fluorouracil affects chiefly the later part of the LGV growth cycle; non-infective forms develop, and the maturation of elementary bodies is blocked. The findings endorse the view that the psittacosis-lymphogranuloma-trachoma group agents are not viruses, but have close affinities with rickettsiae and certain bacteria.
\end{abstract}

\section{INTRODUCTION}

The taxonomic position of the psittacosis-lymphogranuloma-trachoma (PLT) group of organisms, particularly their relation to viruses, is a subject of long-standing controversy (see Weiss, 1955; Bedson, 1959; Moulder, 1964; Andrewes, 1964). Current views on the essential attributes of viruses are more precise than formerly, but the position of the PLT group has remained uncertain, due largely to the equivocal nature of data on some basic properties including their mode of replication. The original studies using light microscopy (e.g. Bedson, Western \& Levy-Simpson, 1930; Findlay, Mackenzie \& MacCallum, 1938; Bedson \& Gostling, 1954) showed these agents to be obligate intracellular parasites with a complex growth cycle. This involved the development of cytoplasmic inclusions containing relatively large particles (c. $1 \mu$ ) termed initial bodies, which appeared to multiply by binary fission and give rise to a population of smaller infective particles $(c .0 .3 \mu)$ termed elementary bodies. However, some crucial aspects of the growth cycle were not defined. The mode of entry into the host cell, the possibility of eclipse or breakdown of the invading particles, the origin of initial bodies and the mechanism of elementary body formation, all remained conjectural.

Electron microscopical studies on the development of PLT agents have been under- 
taken in several laboratories (Gaylord, 1954; Mitsui et al. 1958; Higashi, 1959; Litwin, Officer, Brown \& Moulder, 1961; Bernkopf, Mashiah \& Becker, 1962), but these observations did not at once clarify the relationship of the different types of particles, either to the host cell or to each other. Examination of cell cultures at known intervals following infection suggested the occurrence of a virus-like matrix prior to the appearance of dividing particles (Tajima, Nomura \& Kubota, 1957; Armstrong, Valentine \& Fildes, 1963; Higashi, Tamura \& Iwanaga, 1962; Mitsui, Fujimoto \& Kajima, 1964). Re-investigation of this somewhat surprising observation led to recognition of a misleading technical artifact which affects the morphology of developing PLT organisms, even though the host cell may be well preserved (Armstrong \& Reed, 1964). In HeLa cells infected with the agent of lymphogranuloma venereum (LGV) it was shown that elementary bodies from the inoculum entered cells as a result of phagocytosis; within $6 \mathrm{hr}$, and with no loss of structural integrity, engulfed particles transformed directly into discrete initial bodies. Previous descriptions of a viral matrix in PLT-infected cells, including our own, evidently referred to the products of accidental disruption of initial bodies caused by inadequate fixation. Similar findings have been reported recently by Higashi (1965) following use of improved techniques.

Susceptibility of the PLT group to antibiotics is well known. Weiss (1950) drew attention to the development of abnormally large particles in the presence of penicillin, and Moulder (1964) has pointed to an analogy with penicillin-induced bacterial spheroplasts; but so far there has been no satisfactory description of the penicillin forms in fine structural terms.

The present paper describes experiments aimed at further defining the morphological characteristics of the LGV agent, and its replicating mechanism in cell cultures. In addition, observations have been made on the effects of penicillin and of 5-fluorouracil (5-FU) on the structure and multiplication of this agent.

\section{METHODS}

Tissue culture and inoculation. HeLa cell monolayers were grown in Hanks balanced salt solution with $0.5 \%(\mathrm{w} / \mathrm{v})$ lactalbumen hydrolysate, $10 \%(\mathrm{v} / \mathrm{v})$ calf serum and $200 \mu \mathrm{g} . / \mathrm{ml}$. streptomycin. After inoculation the cultures were normally maintained on medium 199 with $5 \%(\mathrm{v} / \mathrm{v})$ horse serum; but in experiments involving the use of 5-FU, Eagle's medium with $10 \%(\mathrm{v} / \mathrm{v})$ horse serum was employed. 5-FU was added to the medium at a concentration of $4 \mu \mathrm{g} . / \mathrm{ml}$. and the cells were pretreated with this inhibitor for $18 \mathrm{hr}$ prior to inoculation. The sodium salt of benzyl penicillin was used at a concentration of $0.1 \mathrm{unit} / \mathrm{ml}$. An inoculum containing the JH strain of LGV agent was prepared by treatment of $42 \mathrm{hr}$-infected HeLa cells for $4 \mathrm{~min}$. in the MSE ultrasonic disintegrator. Bottles to be inoculated were rinsed with Hanks solution, the cell sheet was covered with LGV suspension and incubated for $30 \mathrm{~min}$. at $36^{\circ}$; the inoculum was then removed, the monolayers rinsed with Hanks solution and maintenance medium added. Cultures were incubated at $36^{\circ}$.

Infectivity titrations were made in $\mathrm{HeLa}$ cell cultures using a method of inclusion counting, based on that described by Furness, Graham \& Reeve, (1960).

Light microscopy. Sample coverslips were removed after periods of 18, 24, 48 and $72 \mathrm{hr}$ following inoculation. Some were observed in the living state by phase-contrast; 
others were rinsed in Hanks solution, fixed in methanol or formol-saline, and stained by the Giemsa method.

Electron microscopy. Inoculated and control cultures, including those with added 5-FU, were prepared for thin-section electron microscopy at intervals from 15 to $72 \mathrm{hr}$ from the time of inoculation. Penicillin-treated cultures were sampled at 24 and $48 \mathrm{hr}$ stages only. Processing was as follows: after a brief rinse with Hanks solution the monolayers were fixed in situ for $5 \mathrm{~min}$. with the solution of Kellenberger, Ryter \& Séchaud (1958), i.e. $1 \%(\mathrm{w} / \mathrm{v})$ osmium tetroxide in veronal-acetate-saline buffer, with calcium ions, at pH $6 \cdot 1$. They were then pushed gently from the glass; the contents of several bottles were pooled, and fixation continued for $1 \mathrm{hr}$ at $4^{\circ}$. This was followed by $1 \mathrm{hr}$ in the $0.5 \%$ (w/v) buffered uranyl acetate washing solution of Kellenberger et al. (1958), and embedding in Vestopal W or in pre-polymerized methacrylate. Contrast in the sections was enhanced by staining with uranyl acetate or with lead citrate as recommended by Reynolds (1963). Micrographs were obtained with a Philips EM 75b electron microscope.

\section{RESULTS}

\section{Infectivity titrations}

HeLa cells inoculated with LGV agent and incubated for $48 \mathrm{hr}$. were resuspended in a volume of fresh medium equal to that in the original bottles. After treatment for $4 \mathrm{~min}$. in the ultrasonic disintegrator a preparation grown in medium containing neither penicillin nor 5-FU gave a titre of $1.6 \times 10^{6}$ inclusion-forming units (i.f.u.) per $\mathrm{ml}$. when titrated on fresh monolayers. The corresponding $48 \mathrm{hr}$ preparation in the presence of penicillin or 5-FU possessed no detectable infectivity. There was again no sign of infectivity in specimens grown for $72 \mathrm{hr}$ in the presence of 5-FU. After $72 \mathrm{hr}$ in the presence of penicillin scattered inclusions were produced in the test monolayer, but infectivity of the material was well below the lower limit of accuracy of the titration method, i.e. approximately $10^{3}$ i.f.u. $/ \mathrm{ml}$.

\section{Light microscopy}

Phase-contrast observations. In unfixed monolayers typical cytoplasmic inclusions were visible in more than $75 \%$ of the cells $18 \mathrm{hr}$ after inoculation; each inclusion contained a cluster of discrete, rounded and optically dense initial bodies with a diameter of approximately $1 \mu$. After $24 \mathrm{hr}$ inclusions were larger and the initial bodies seemed to be more numerous. If the monolayer was passed successively through the fixative and washing solutions of Kellenberger et al. (1958) the initial bodies became more clearly visible through enhanced contrast (Pl. 1, fig. 1); on the other hand, brief immersion in the standard fixative of Palade (1952) produced inclusions with ill-defined or diffuse contents. In $48 \mathrm{hr}$ specimens the inclusions were massive and contained innumerable minute elementary bodies, measuring less than $0.5 \mu$. These were frequently in a state of vigorous Brownian movement.

In penicillin-treated monolayers abnormal cytoplasmic inclusions were detectable in a majority of cells $24 \mathrm{hr}$ after inoculation; in general they were smaller than normal inclusions at the same stage, and instead of the usual initial bodies they contained a small number (usually only one or two) of oval or rounded bodies corresponding to the penicillin forms of other PLT agents as described by Weiss (1950). They were much larger than normal initial bodies, and commonly vacuolated (Pl. 3, fig. 7). Further 
enlargement of the penicillin forms was evident after $48 \mathrm{hr}$ and $72 \mathrm{hr}$, with no apparent increase in their number; many had assumed the form of vesicular structures with a dense crescentic margin. There was no sign of elementary bodies. Immersion of the monolayers in Palade's fixative for a few minutes caused many of the penicillin forms to rupture.

In the cultures treated with 5-FU cytoplasmic inclusions were readily seen in the living cells $24 \mathrm{hr}$ after inoculation, and subsequently they enlarged in the normal way to occupy much of the cell. At first their contents were not unlike the normal initial bodies but from $48 \mathrm{hr}$ onwards there was marked variation in the appearance of inclusions in different cells (Pl. 4, fig. 10). Some small inclusions contained only a few rather large particles; elsewhere the inclusions were larger, and these contained particles of various sizes at least some of which resembled elementary bodies.

Stained monolayers. A comparison of fixed and stained monolayers with the parallel cultures examined by phase-contrast suggested that normal initial bodies are deformed and sometimes ruptured as a result of methanol fixation. The larger penicillin forms and those developing in the presence of 5-FU showed even greater susceptibility to methanol damage. Formol-saline preserved the inclusions in a form nearer to that seen in the living cells.

\section{Electron microscopy}

Normal structure and fate of initial bodies. Cytoplasmic LGV inclusions are welldefined vesicular structures, sometimes loculated, situated in close relation to the Golgi complex of the cell. A single unit membrane limits the inclusion, separating its contents from the surrounding cytoplasm. Study of sequential stages following inoculation suggests that the typical juxtanuclear inclusion arises from coalescence of the phagocytic vesicles containing individual ingested elementary bodies; indirectly, therefore, the inclusion wall is derived from the host cell membrane. Sections of inclusions at the $15 \mathrm{hr}$ stage show a collection of discrete initial bodies suspended freely in an electron-transparent medium (Pl. 1, fig. 2). Initial bodies are rounded or oval in shape, and measure between 1 and $1.5 \mu$ in diameter. Each is enclosed in a limiting envelope which, in appropriate planes of section, is seen to be a bilaminar structure. Both layers are typical unit membranes, and approximately $7 \mathrm{~m} \mu$ in thickness (Pl. 2, figs. 3, 4). A clear zone about $10 \mathrm{~m} \mu$ wide normally separates the two dense layers, though in many places the outer is found to be lifted slightly with a consequent widening of the intervening clear zone. The inner layer of the envelope everywhere adheres closely to the contents of the initial body. Two internal components are recognizable in all sectioned initial bodies (Pl. 1, fig. 2; Pl. 2. figs. 3, 4). Dense granular material consisting largely of ribosome-like particles occupies the peripheral regions of the organism, and also extends in the form of irregular strands into the centre; here there are intervening areas of lower electron density containing a network of very fine filaments. There are obvious similarities in terms of fine structure, between LGV initial bodies and many bacterial and rickettsial cells. The two layers of the limiting envelope can be compared, respectively, to the cell wall and cytoplasmic membrane as found in Gramnegative bacteria; whilst the filamentous and granular elements are similar in character to bacterial nuclear and cytoplasmic regions.

Comparison of LGV-infected cells 15,18 and $24 \mathrm{hr}$ after inoculation reveals an increase both in the size of inclusions and in the number of contained initial bodies. 
Moreover, initial bodies showing constricted or dumb-bell profiles are very common and are strong evidence for the view that the LGV agent multiplies by a process of fission (P1. 1, fig. 2; Pl. 2, figs. 3, 5). It appears that division of an initial body is preceded by enlargement and slight elongation of the organism, that this is followed by the development of a circumferential constriction at or near to the mid-point, and that final separation of the two halves produces a pair of virtually identical daughter initial bodies. The two layers of the envelope remain distinct and in close apposition whilst growing centripetally at the point of constriction; and there is no sign of preliminary cross-wall formation. A closely comparable mode of cell divisions has been described in certain Gram-negative bacteria, and in rickettsiae (Conti \& Gettner, 1962; Bladen \& Waters, 1963; Ito \& Vinson, 1965).

Some signs of a departure from this pattern of multiplication are detectable in the cultures examined $24 \mathrm{hr}$ after inoculation, and are quite obvious in the 48 and $72 \mathrm{hr}$ specimens. The initial bodies, though still readily identified, tend to be smaller than in the early part of the growth cycle. Measurement of dividing forms suggests that organisms of progressively smaller size are being formed. Where the diameter of the structure falls much below $1 \mu$ there are additional signs of modified internal organization: the filamentous and granular elements tend to separate, with the 'nuclear' material becoming limited to a central mass of high density whilst the ribosome-like granules are confined to the periphery (Pl. 2, fig. 4). Most inclusions from $48 \mathrm{hr}$ onwards thus contain a wide spectrum of particles, ranging from initial bodies down to small, dense-centred forms that are typical elementary bodies (P1. 2, fig. 6). Profiles such as the comparatively small dividing form shown in Pl. 2, fig. 5, are of particular interest, as this would seem to represent the formation of a pair of elementary bodies. It is seen that the two layers of the limiting envelope are becoming widely separated, as the inner layer retracts in company with the condensed contents of the organism.

The prominent external membrane that is a familiar feature of all PLT-group elementary bodies evidently corresponds morphologically with only the outer layer of the bilaminar envelope possessed by initial bodies. In sections through mature elementary bodies (Pl. 2, fig. 6) it becomes difficult as a rule to identify more than a small part of the inner layer of the envelope, so intimate is its association with the dense core structure.

Effects of penicillin. $24 \mathrm{hr}$ after inoculation, in the presence of the antibiotic, cytoplasmic inclusions containing abnormal developmental forms of LGV agent are readily identified (Pl. 3, fig. 9). The penicillin forms appear as large vacuolated organisms measuring about $10 \mu$, occasionally more, in diameter. There is a complete limiting envelope, consisting of two layers which in thickness and spacing appear to be much the same as in normal initial bodies. Inside are the usual granular and fibrillar components, but in contrast to normal initial bodies the relative development of these components is very variable. Particularly in the largest penicillin forms there is often a striking preponderance of the filamentous, or 'nuclear', material (Pl. 3, fig. 8). Vacuoles are usually multiple, and bounded by a single membrane; points of continuity between vacuoles and the clear zone between the layers of the limiting envelope can be found, suggesting that vacuolation may have developed through ballooning of the envelope. Vacuoles are larger and more numerous after $48 \mathrm{hr}$, resulting in correspondingly greater morphological distortion. This evidently accounts for the crescentic forms observed in living cultures by phase-contrast, and in thin sections gives rise 
to bizarre profiles. Deep invaginations from the inner layer of the envelope are sometimes present, producing irregular internal subdivisions; such organisms, however invariably remain enclosed within a common outer membrane and there is no sign of true division.

Effects of 5-FU. Electron microscopy of the 5-FU-treated cultures suggests that, in contrast to penicillin, the concentration of 5-FU used in this experiment has little effect on structure and multiplication of LGV agent during the first $24 \mathrm{hr}$ of growth in HeLa cells. Initial bodies, very similar to those seen normally in infected cell cultures, are present in the inclusions 15 and $24 \mathrm{hr}$ after inoculation. In addition, profiles suggesting fission are also found. By $48 \mathrm{hr}$ most inclusions are generally smaller than they would be normally, and contain a proportion of abnormal initial bodies which show vacuolation and segmentation due to ingrowths from the inner layer of the envelope. After $72 \mathrm{hr}$ (Pl. 4, fig. 11) nearly all of the organisms are obviously affected and many are undergoing fragmentation into irregular debris. Mature elementary bodies are not found.

\section{DISCUSSION}

In recent papers (Armstrong \& Reed, 1964; Higashi, 1964, 1965) evidence was presented that in cell cultures infected with LGV, trachoma or psittacosis agents, initial bodies originate during the first few hours of the growth cycle by enlargement and reorganization of phagocytosed elementary bodies. Factors that initiate and control the transformation remain uncertain, but the influence of the host cell enzymes is suggested by intimate association of the engulfed particles with lysosome-like vesicles in the cell cytoplasm.

Distinct morphological similarities exist between LGV initial bodies, rickettsiae and certain bacterial cells, notably in respect of the limiting envelope and the presence of what may be regarded as 'nuclear' and 'cytoplasmic' internal components. That this is true of the PLT group as a whole is evident from recently published micrographs showing the initial bodies of psittacosis, trachoma and meningopneumonitis agents (Erlandson \& Allen, 1964; Kajima, Sharon \& Pollard, 1964; Higashi, 1965; Anderson, Hopps, Barile \& Bernheim, 1965). The essential form of initial bodies would have been recognized sooner but for their peculiar fragility: an isotonically balanced fixative is required for their adequate preservation, especially in the first $12 \mathrm{hr}$ of intracellular growth. Multiplication of initial bodies during the first $24 \mathrm{hr}$ of growth in HeLa cells is exclusively by fission, without preliminary cross-wall formation; and the daughter organisms retain typical initial body morphology. Division of initial bodies continues beyond the $24 \mathrm{hr}$ stage, but with a gradual reduction of their size. Segregation and condensation of the filamentous and granular internal components then becomes apparent, and the layers of the limiting envelope become widely separated; in this way the particles assume the form of elementary bodies. The transformation is, in effect, the reverse of that observed during the first few hours of the growth cycle. By $72 \mathrm{hr}$ particles of the elementary body type predominate, and forms that are obviously dividing are found less frequently. It seems likely that once the filamentous material, that is assumed to contain DNA, becomes condensed it does not replicate further until the particle enters a new host cell. At all developmental stages it is possible to identify the two layers of the limiting envelope, and the same two internal components; 
however, the arrangement of these elements, relative to one another, differs appreciably in the particles seen at each stage of the growth cycle. The different finestructural organization of initial and elementary bodies evidently reflects the markedly different biological properties of these particles.

As expected, growth and multiplication of LGV agent was considerably modified in the presence of penicillin. Adsorption and engulfment of elementary bodies, and their subsequent enlargement are clearly not prevented by the antibiotic. However, the initial bodies do not multiply, but develop into large, abnormal organisms which entirely fail to revert to elementary body form. The present findings are in full agreement with the conclusions of Weiss (1950) that the effect of penicillin on the PLT group is essentially an interference with fission. From the structure of the penicillin forms it can be deduced that the outer layer of the envelope fails to participate in attempts at division. Members of the PLT group have been shown to contain muramic acid, a characteristic component of bacterial cell-wall mucopeptide (Perkins \& Allison, 1963); since penicillin is known to inhibit mucopeptide synthesis in bacteria it probably acts in the same way on the PLT group. Disproportionate development of 'nuclear' and 'cytoplasmic' components, as found in some of the penicillin forms, suggests that an additional effect may be disturbance of the normal balance of nucleoprotein synthesis. Spheroplasts induced by treatment of Gram-negative bacteria with penicillin are swollen and vacuolated structures, osmotically labile and dependent on a medium of high tonicity for stabilization (Lederberg \& St Clair, 1958; McQuillen, 1960; Martin, 1963). At the fine structural level (Thorsson \& Weibull, 1958; Hines, Freeman \& Pearson, 1964; Weibull \& Mohri, 1965) spheroplasts are markedly pleomorphic, but often bear a close resemblance to the penicillin forms seen in the present study.

5-FU is known to become incorporated into ribonucleic acid as a uracil analogue in mammalian cells, bacteria and viruses; replication of DNA is also impaired due to an inhibition of thymine synthesis (Cohen et al. 1958; Horowitz, Saukkonen \& Chargaff, 1960). The compound evidently interferes also with synthesis of bacterial cell walls (Tomasz \& Borek, 1960; Rogers \& Perkins, 1960). In the present study the effect of 5-FU is seen mainly in the later stages of the LGV growth cycle. Formation of initial bodies and their multiplication proceeds normally for at least a few hours, and there is marked variation from cell to cell concerning the point in the growth cycle at which definite effects of 5-FU are seen. Eventually, however, atypical initial bodies develop; they are not unlike some of the penicillin forms, which suggests an effect on the cell wall, but they show a marked tendency to spontaneous fragmentation.

In cytochemical studies using the acridine orange fluorescence technique (Pollard, Starr, Tanami \& Elliott, 1960; Tanami, Pollard \& Starr, 1961; Pollard \& Starr, 1962) it was observed that treatment of cell cultures with 5-FU $14 \mathrm{hr}$ after inoculation with PLT agents resulted in highly abnormal patterns of diffuse RNA-containing material in the region of the cytoplasmic inclusions. This was interpreted as host-cell-contributed material. However, fine structural appearances after fixation by Kellenberger's method suggest that inclusions which develop in the presence of 5-FU contain discrete though abnormal forms of the infective agent; no diffuse matrix is demonstrable. Damage due to alcohol-containing fixatives could perhaps give rise to an appearance simulating a diffuse matrix when viewed by fluorescence microscopy.

Moulder (1964) has presented a detailed and lucid account of evidence bearing upon the possible relationship between PLT agents and bacteria. Additional biochemical 
studies have shown that PLT agents possess at least some degree of autonomous energy metabolism (Weiss, Myers, Dressler \& Chun-Hoon, 1964), though they depend upon ATP supplied by the host cell as an energy substrate (Weiss, 1965). The present findings lend further support to the concept of the PLT group as complex organisms, well adapted to a life of intracellular parasitism, and with close affinities to the rickettsiae. They have only a superficial likeness to viruses, as these are presently defined. In purely morphological terms, initial bodies of the PLT group and the rickettsiae both have much in common with the free-living Gram-negative bacteria.

The authors are indebted to Dr R. C. Valentine for two micrographs taken with the Philips EM 200 electron microscope, and reproduced as Pl. 2, figs. 4 and 6; to $\mathrm{Mr}$ M. R. Young for the phase-contrast micrographs, and to Roche Products Ltd. for the gift of 5-fluorouracil.

\section{REFERENCES}

Anderson, D. R., Hopps, H. E., Barile, M. F. \& Bernheim, B. C. (1965). Comparison of the ultrastructure of several Rickettsiae, Ornithosis virus and Mycoplasma in tissue culture. J. Bact. 90, 1387.

ANDrEwes, C. H. (1964). Viruses of Vertebrates. London: Baillière, Tindall and Cox.

Armstrong, J. A. \& Reed, S. E. (1964). Nature and origin of initial bodies in lymphogranuloma venereum. Nature, Lond. 201, 371.

Armstrong, J. A., Valentine, R. C. \& Fildes, C. (1963). Structure and replication of the trachoma agent in cell cultures as shown by electron microscopy. J. gen. Microbiol. 30, 59.

BeDson, S. P. (1959). The psittacosis-lymphogranuloma group of infective agents. Jl R. Inst. publ. Hlth 22, 131.

Bedson, S. P. \& Gostling, J. V. T. (1954). A study of the mode of multiplication of psittacosis virus. Br. J. exp. Path. 35, 299.

Bedson, S. P., Western, G. T. \& Levy-Simpson, S. (1930). Observations on the aetiology of psittacosis. Lancet i, 235, 345.

Bernkopf, H., MASHiAH, P. \& BeCKer, Y. (1962). Correlation between morphological and biochemical changes and the appearance of infectivity in FL cell cultures infected with trachoma agent. Ann. N.Y. Acad. Sci. 98, Art. 1, 62.

Bladen, H. A. \& WATERs, J. F. (1963). Electron microscopic study of some strains of Bacteriodes. J. Bact. 86, 1339.

Cohen, S. S., Flaks, J. G., Barnes, H. D., Loeb, M. R. \& Lichtenstern, J. (1958). The mode of action of 5-fluorouracil and its derivatives. Proc. natn. Acad. Sci., U.S.A. 44, 1004.

CONTI, S. F. \& GeTtNeR, M. E. (1962). Electron microscopy of cellular division in Escherichia coli. J. Bact. 83, 544 .

Erlandson, R. A. \& Allen, E. G. (1964). The ultrastructure of meningopneumonitis. Virology 22, 410.

Findlay, G. M., Mackenzie, R. D. \& MacCallum, F. O. (1938). A morphological study of the virus of lymphogranuloma inguinale (climatic bubo). Trans. R. Soc. trop. Med. Hyg. $32,183$.

Furness, G., Graham, D. M. \& ReEve, P. (1960). The titration of trachoma and inclusion blenorrhoea viruses in cell cultures. J. gen. Microbiol. 23, 613 .

GAYLORD, W. H. (1954). Intracellular forms of meningopneumonitis virus. J. exp. Med. 100, 575.

Higashi, N. (1959). Electron microscopy of viruses in thin sections of cells grown in culture. Progr. med. Virol. $2,43$.

Higashi, N. (1964). Mode of reproduction of the psittacosis-lymphogranulomatrachoma (PLT) group viruses. Internat. Rev. exp. Path. 3, 35.

HigASHI, N. (1965). Electron microscopic studies on the mode of reproduction of trachoma virus and psittacosis virus in cell cultures. Exp. molec. Path. 4, 24.

Higashi, N., Tamura, A. \& Iwanaga, M. (1962). Developmental cycle and reproductive mechanism of the meningopneumonitis virus in strain L cells. Ann. N.Y. Acad. Sci. 98, Art. 1, 100.

Hines, W. D., Freeman, B. A. \& Pearson, G. R. (1964). Fine structure of Brucella suis spheroplasts. J. Bact. 87, 1492.

Horowitz, J., Saukkonen, J. J. \& ChargafF, E. (1960). Effects of fluoropyrimidines on the synthesis of bacterial proteins and nucleic acids. J. biol. Chem. 235, 3266.

ITO, S. \& Vinson, J. W. (1965). Fine structure of Rickettsia quintana cultivated in vitro and in the louse. J. Bact. 89, 481. 

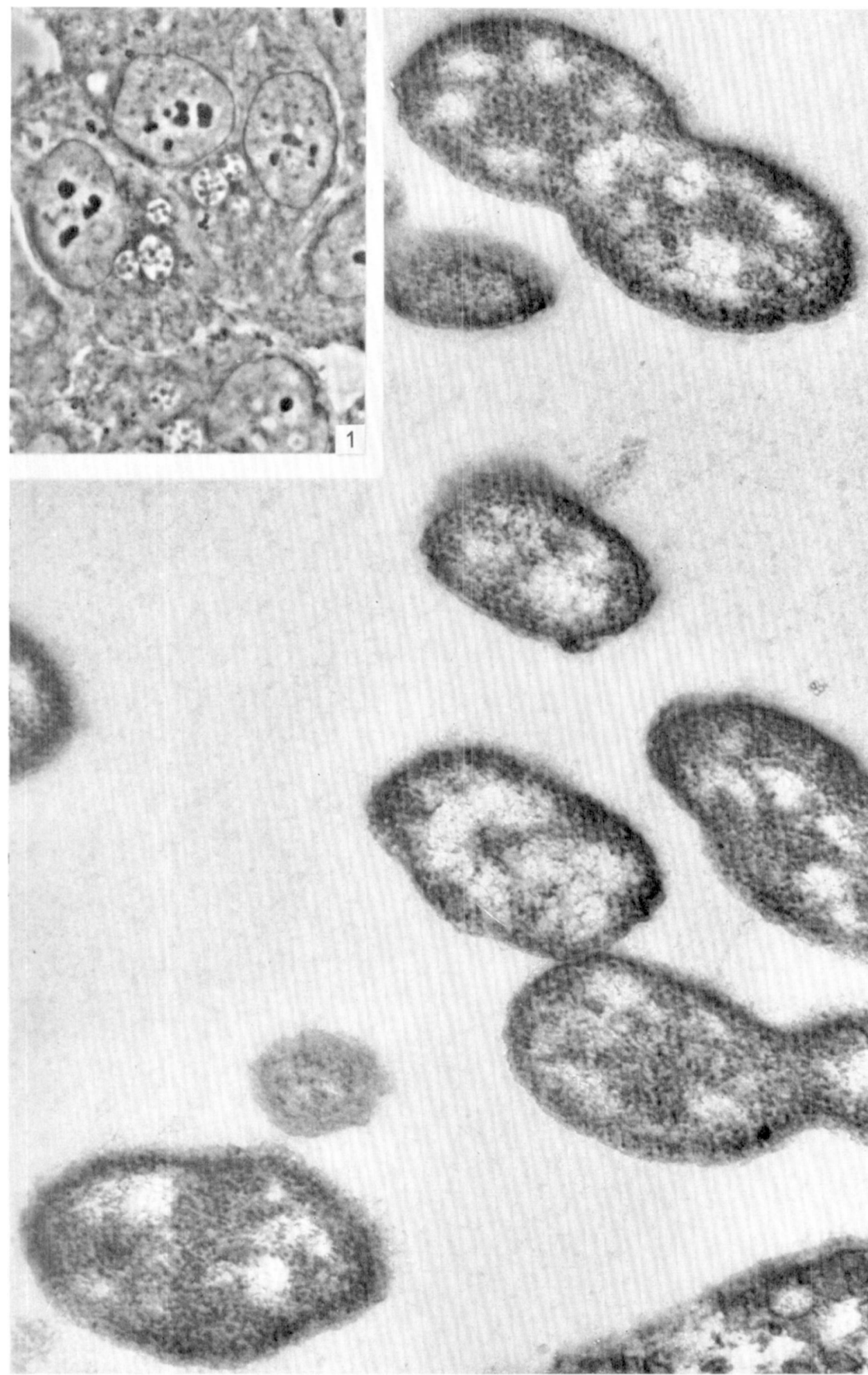
Journal of General Microbiology, Vol. 46, No. 3

Plate 2
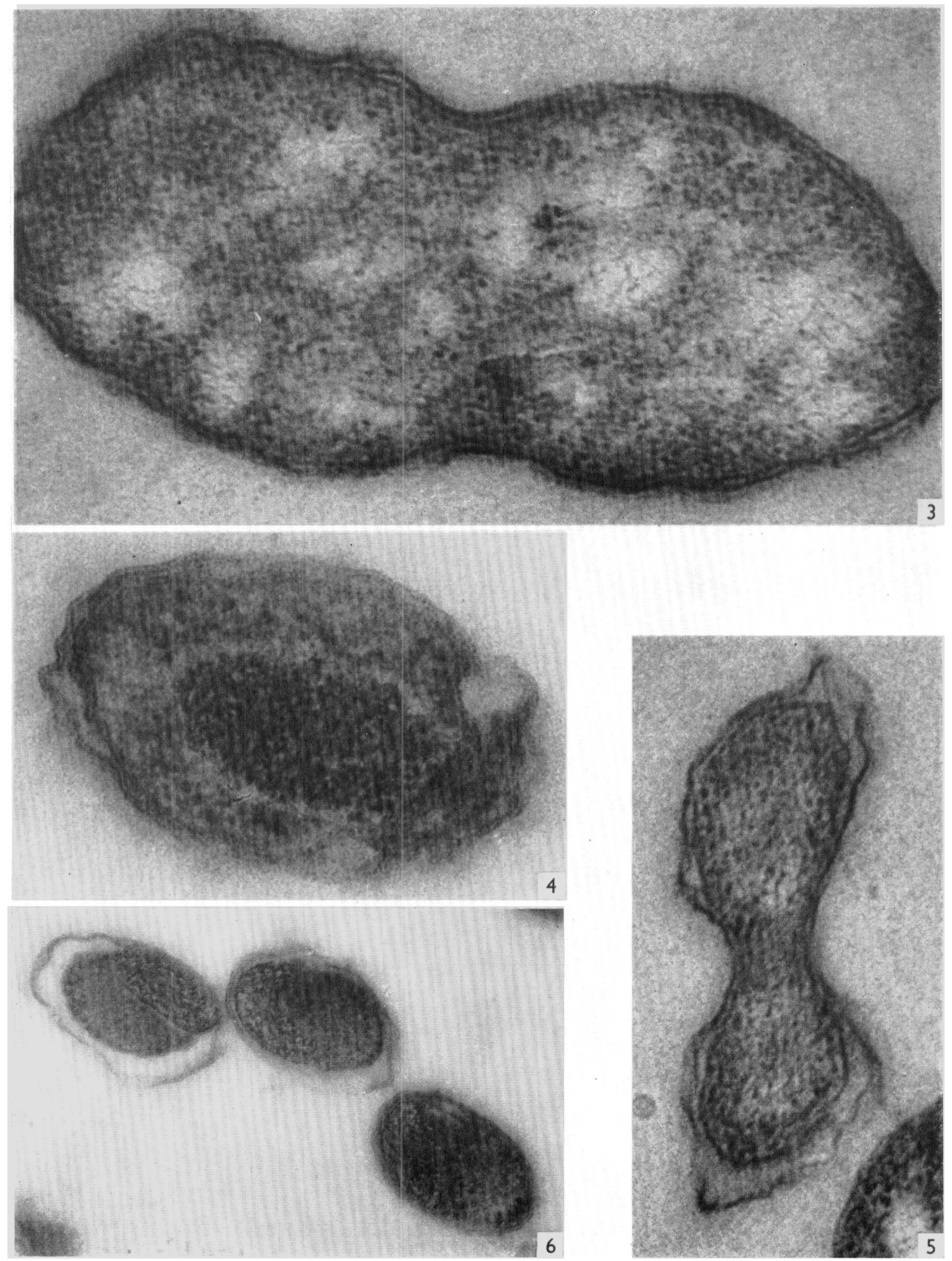

J. A. ARMSTRONG AND S. E. REED 
Journal of General Microbiology, Vol. 46, No. 3

Plate 3
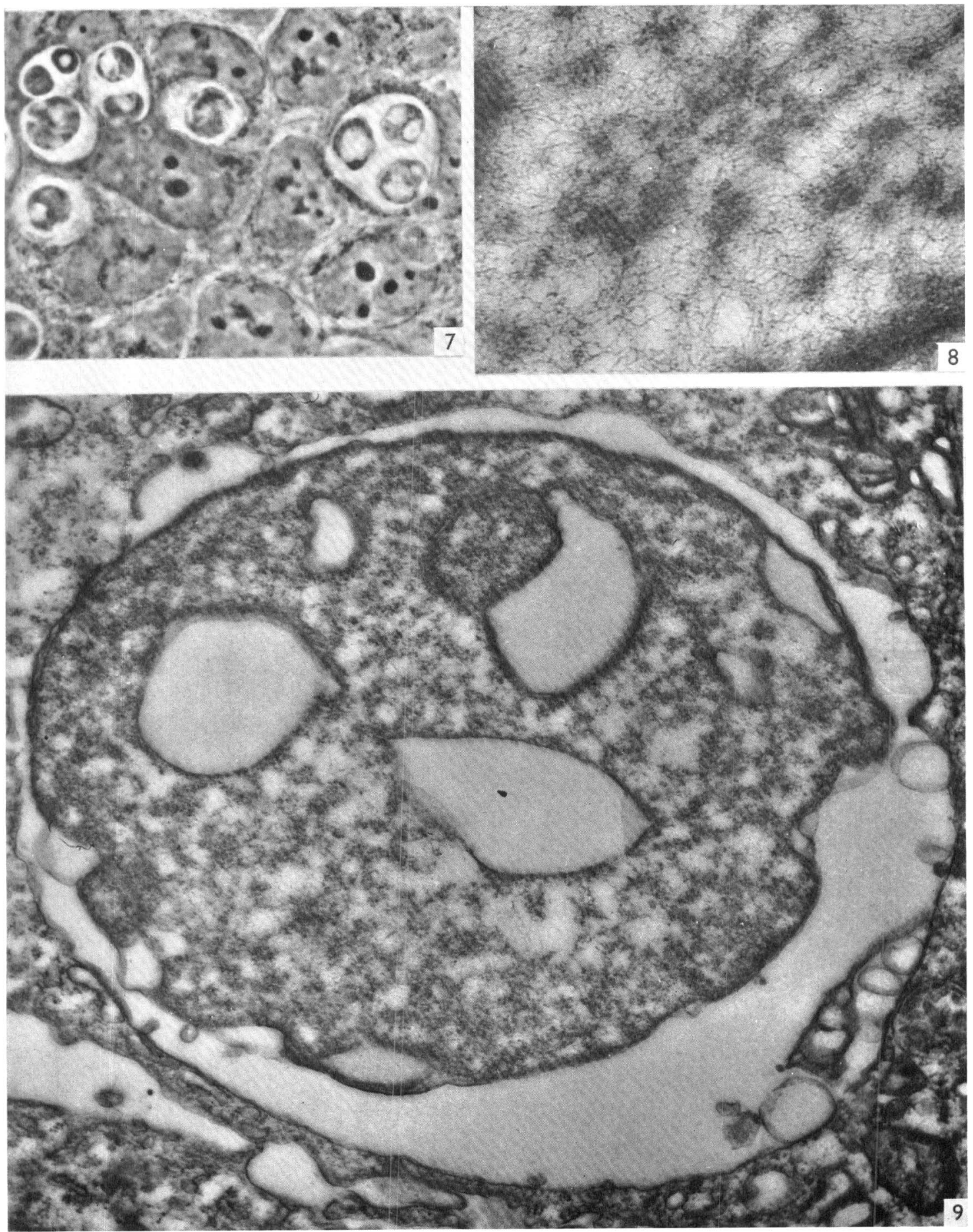

J. A. ARMSTRONG AND S. E.REED 


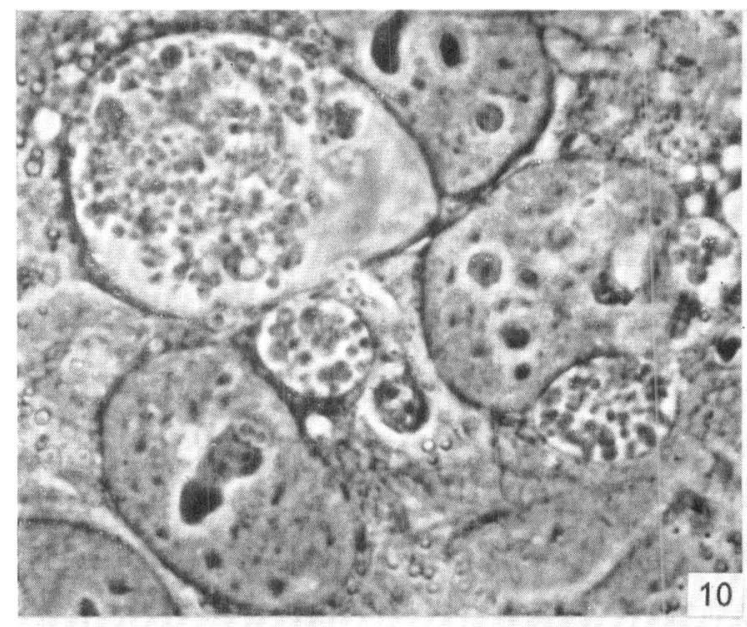

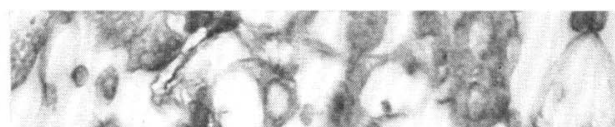

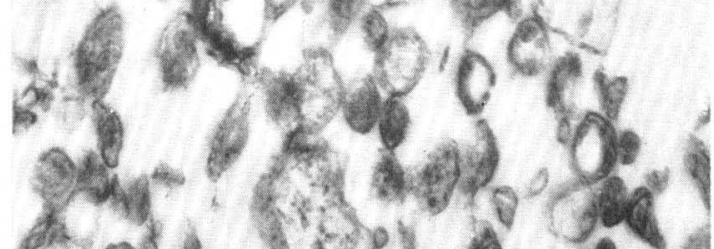
parar a

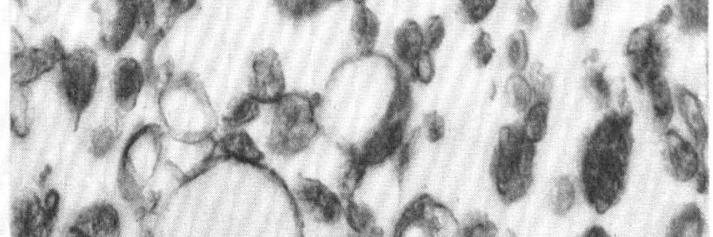

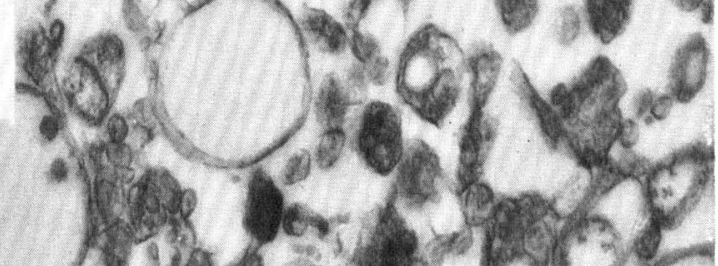

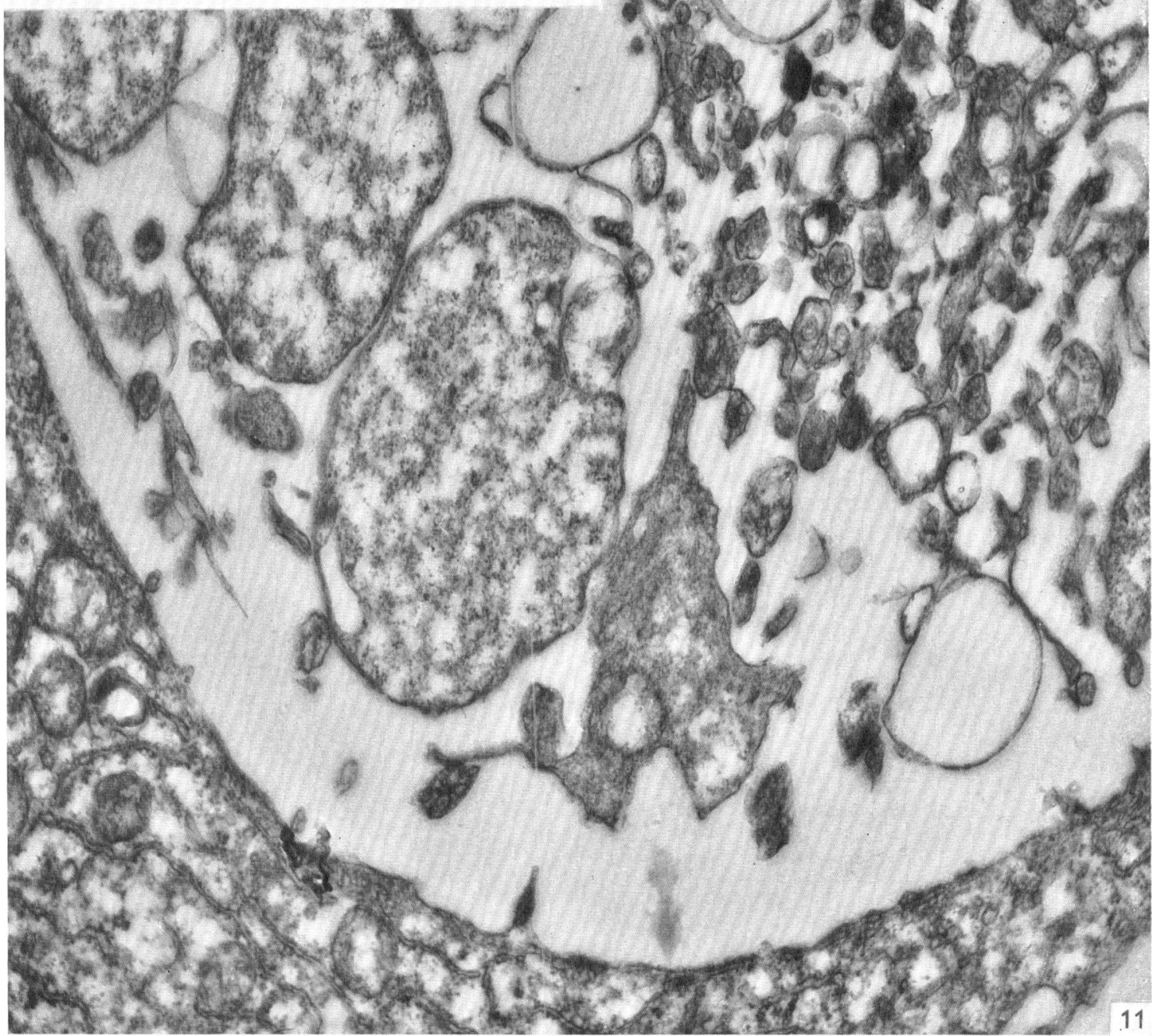


Kajima, M., Sharon, N. \& Pollard, M. (1964). Electron microscopy of latent psittacosis virus in McCoy cells. J. Bact. 88, 709.

Kellenberger, E., Ryter, A. \& Séchaud, J. (1958). Electron microscopic studies of DNA-containing plasma. II. Vegetative and mature phage DNA as compared with normal bacterial nucleoids in different physiological states. J. biophys. biochem. Cytol. 4, 671.

Lederberg, J. \& St Clair, J. (1958). Protoplasts and L-type growth of Escherichia coli. J. Bact. 75, 143.

Litwin, J., Officer, J. E., Brown, A. \& Moulder, J. W. (1961). A comparative study of the growth cycles of different members of the psittacosis group in different host cells. J. infect. Dis. 109, 251.

MarTin, H. H. (1963). Bacterial protoplasts-a review. J. theoret. Biol. 5, 1.

MCQuillen, K. (1960). In The Bacteria, vol. I. Ed. by I. C. Gunsalus and R. Y. Stanier. New York and London: Academic Press.

Mitsui, Y., Fujimoto, M. \& KaJIMA, M. (1964). Development and morphology of trachoma agent in the yolk sac as revealed by electron microscopy. Virology 23, 30.

Mitsui, Y., Suzuki, A., Hanabusa, J., Minoda, R., Ogata, S., Funushima, S. \& Miura, M. (1958). Structures of the initial bodies of trachoma inclusion as revealed in section by electron microscopy. Virology 6, 137.

Moulder, J. W. (1964). The Psittacosis Group as Bacteria. New York: John Wiley and Sons, Inc.

PalADE, G. E. (1952). A study of fixation for electron microscopy. J. exp. Med. 95, 285.

Perkins, H. R. \& Allison, A. C. (1963). Cell wall constituents of rickettsiae and psittacosis-lymphogranuloma organisms. J. gen. Microbiol. 30, 469.

Pollard, M. \& StarR, T. (1962). Study of intracellular virus with acridine orange fluorochrome. Progr. med. Virol. 4, 54.

Pollard, M., Starr, T., Tanami, Y. \& Elliott, A. (1960). Cytochemical effects of substituted pyrimidines on psittacosis virus. Proc. Soc. exp. Biol. Med. 105, 476.

REYNOLDS, E. S. (1963). The use of lead citrate at high $\mathrm{pH}$ as an electron-opaque stain in electron microscopy. J. Cell Biol. 17, 208.

Rogers, H. J. \& Perkins, H. R. (1960). 5-Fluorouracil and mucopeptide biosynthesis by Staphylococcus aureus. Biochem. J. 77, 448.

Taлma, M., Nomura, Y. \& Kubota, Y. (1957). Structure and development of viruses of the psittacosis-lymphogranuloma group observed in the electron microscope. J. Bact. 74, 605.

Tanami, Y., Pollard, M. \& Starr, J. J. (1961). Replication pattern of psittacosis virus in a tissue culture system. Virology 15, 22.

Thorsson, K. G. \& Weibull, C. (1958). Studies on the structure of bacterial L-forms, protoplasts and protoplast-like bodies. J. Ultrastr. Res. 1, 412.

TOMASZ, A. \& BOREK, E. (1960). The mechanism of bacterial fragility produced by 5 -fluorouracil; the accumulation of cell wall precursors. Proc. natn. Acad. Sci., U.S.A. 46, 324.

WeIBull, C. \& Mohri, T. (1965). Fixation of bacterial L-forms for electron microscopy. J. Bact. 89, 901.

WeISS, E. (1950). The effect of antibiotics on agents of the psittacosis-LGV group. I. The effect of penicillin. $J$. infect. Dis. 87, 249.

WEISS, E. (1955). The nature of the psittacosis-lymphogranuloma group of micro-organisms. A. Rev. Microbiol. 9, 227.

WEISS, E. (1965). Adenosine triphosphate and other requirements for the utilization of glucose by agents of the psittacosis-trachoma group. J. Bact. 90, 243.

Weiss, E., Myers, W. F., Dressler, H. R. \& Chun-Hoon, H. (1964). Glucose metabolism by agents of the psittacosis-trachoma group. Virology 22, 551.

\section{EXPLANATION OF PLATES}

\section{Plate 1}

Fig. 1. HeLa cells in a monolayer culture $18 \mathrm{hr}$ after LGV inoculation. Discrete initial bodies are visible in the vesicular cytoplasmic inclusions. Phase-contrast, after Kellenberger fixation $(\times 1350)$.

Fig. 2. Electron microscopical appearance of initial bodies in a cytoplasmic inclusion $18 \mathrm{hr}$ after inoculation. A dividing form is seen at the top, and possibly another at lower right $(\times 64,000)$.

\section{Plate 2. Electron micrographs}

Fig. 3. Section through a dividing initial body, seen at higher magnification. Note the elongated shape and developing central constriction, also the bilaminar character of the limiting envelope $(\times 120,000)$. 
Fig. 4. A particle of transitional type in a $48 \mathrm{hr}$ inclusion, interpreted as intermediate between the typical initial body and elementary body forms. The filamentous 'nuclear' material is seen here as a central dense mass, and both layers of the envelope have unit-membrane structure $(\times 104,000)$.

Fig. 5. Thin section profile of a small dividing particle in a $48 \mathrm{hr}$ inclusion. The layers of the envelope are more widely separated than in initial bodies, and the inner layer adheres to the particle contents $(\times 120,000)$.

Fig. 6. Section through three morphologically mature elementary bodies $(\times 100,000)$.

\section{Plate 3}

Fig. 7. HeLa cell monolayer $24 \mathrm{hr}$ after LGV inoculation, in the presence of penicillin. The inclusions contain large penicillin forms of the LGV agent. Phase-contrast after Kellenberger fixation $(\times 1300)$ Fig. 8. Thin section illustrating the predominantly filamentous nature of the interior of a penicillin form, $48 \mathrm{hr}$ after inoculation $(\times 64,000)$.

Fig. 9. Section of $24 \mathrm{hr} \mathrm{LGV} \mathrm{inclusion,} \mathrm{in} \mathrm{the} \mathrm{presence} \mathrm{of} \mathrm{penicillin.} \mathrm{It} \mathrm{contains} \mathrm{a} \mathrm{single,} \mathrm{vacuolated}$ penicillin form of LGV agent $(\times 32,000)$.

\section{Plate 4}

Fig. 10. HeLa cell monolayer $72 \mathrm{hr}$ after LGV inoculation, in the presence of 5-fluorouracil. The inclusions vary in size, with irregular and poorly defined contents. Phase contrast after Kellenberger fixation $(\times 1300)$.

Fig. 11. Electron microscopical appearance $72 \mathrm{hr}$ after inoculation in the presence of 5-fluorouracil. The inclusion is of about normal size, but the contained particles are pleomorphic. Some resemble misshapen initial bodies. There are numerous irregular membrane-bound fragments, but no mature elementary bodies $(\times 32,000)$. 